\title{
Aluminum chloride: A highly efficient catalyst for addition of amines to carbodiimides to synthesize substituted guanidines
}

\author{
ZHU XueHua ${ }^{1}$, XU Fan $^{1 *} \&$ SHEN Qi ${ }^{1,2 *}$ \\ ${ }^{1}$ Key Laboratory of Organic Synthesis of Jiangsu Province, College of Chemistry, Chemical Engineering and Materials Science, Dushu Lake \\ Campus, Soochow University, Suzhou 215123, China; \\ ${ }^{2}$ State Key Laboratory of Organometallic Chemistry, Shanghai Institute of Organic Chemistry, Chinese Academy of Sciences, Shanghai 200032, \\ China
}

Received December 27, 2011; accepted February 13, 2012; published online July 4, 2012

\begin{abstract}
A catalytic addition of amine $\mathrm{N}-\mathrm{H}$ bonds to carbodiimides using aluminum chloride as a Lewis acid catalyst is developed. The reaction proceeds under mild conditions without solvent to afford a series of substituted guanidines in good to excellent yields using a wide range of amines as substrates. Evidence of the proposed mechanism is provided by in situ infrared spectroscopy.
\end{abstract}

aluminum chloride, catalysis, guanidine

Citation: Zhu X H, Xu F, Shen Q. Aluminum chloride: A highly efficient catalyst for addition of amines to carbodiimides to synthesize substituted guanidines. Chin Sci Bull, 2012, 57: 3419-3422, doi: 10.1007/s11434-012-5332-7

Guanidines can serve as building blocks for many biologically relevant compounds [1] and are also useful as catalysts in organic synthesis [2-7]. Among the reported routes to multisubstituted guanidines, addition of amines to carbodiimides is undoubtedly the most straightforward and atom-economical one. However, harsh reaction conditions are necessary for the reaction to progress in the absence of catalyst [8]. Some highly active catalysts for this reaction have been developed in recent years, and several organometallic complexes have been found to be effective for this transformation [9-18]. Titanium and vanadium imido complexes are reported to be efficient precatalysts for the addition of primary aromatic amines to carbodiimides to afford the corresponding guanidines. However, secondary amines could not be applied in these reactions because a metalimido complex is the active species in the catalytic process $[9,10]$. For the addition of secondary amines to carbodiimides, lithium silylamide [11], lanthanide amides $[12,13]$, carboranyl-alkoxy-ligated titanium amido complexes [14], half-sandwich lanthanide metal alkyl complexes [15-17], and $\mathrm{ZnEt}_{2}, \mathrm{MgBu}_{2}, n$-BuLi [18], and $\mathrm{Zn}(\mathrm{OTf})_{2}$ [19]

\footnotetext{
*Corresponding authors (email: xufan@ suda.edu.cn; qshen@suda.edu.cn)
}

have been found to be highly active catalysts. Recently, it was also shown that alkyl aluminum exhibits high activity for the catalytic addition of amines to carbodiimides [20]. In these catalytic processes, an amine reacts with an organometallic catalyst to form a metal amido species, which quickly attacks the central carbon of a carbodiimide. More recently, the Lewis acid $\mathrm{Yb}(\mathrm{OTf})_{3}$ was reported by our group to serve as another efficient catalyst for the addition of both primary and secondary amines to carbodiimides [21]. In this case, $\mathrm{Yb}(\mathrm{OTf})_{3}$ may behave as an electrophile to generate an adduct with carbodiimide, and subsequent nucleophilic addition of an amine to the adduct leads to the formation of a guanidine. As part of our continued work in this field, $\mathrm{AlCl}_{3}$, a cheap and readily available Lewis acid, was investigated as a catalyst for the addition of amines to carbodiimides. Herein we report our results using $\mathrm{AlCl}_{3}$ as a catalyst.

It is known that $N, N^{\prime}$-diisopropylcarbodiimide $\left({ }^{i} \mathrm{PrN}=\mathrm{C}=\right.$ $\mathrm{N}^{i} \mathrm{Pr}$ ) does not react with aniline at $60^{\circ} \mathrm{C}$ in the absence of catalyst (Table 1, entry 1). However, addition of $0.5 \mathrm{~mol} \%$ of $\mathrm{AlCl}_{3}$ led to efficient guanylation and the corresponding $N, N^{\prime}, N^{\prime \prime}$-trisubstituted guanidine 1 was obtained in $97 \%$ yield at room temperature after just 5 min under solvent- 
free conditions (entry 2). Several metal chlorides were then tested to assess the influence of the central metal ion on catalytic activity. As shown in Table 1, inferior results compared to those for $\mathrm{AlCl}_{3}$ were obtained when the Lewis acids $\mathrm{FeCl}_{3}, \mathrm{SnCl}_{2}, \mathrm{ZnCl}_{2}$ and $\mathrm{YbCl}_{3}$ were used.

To examine the scope and generality of guanylation catalyzed by $\mathrm{AlCl}_{3}$, the process was extended to various aromatic amines and carbodiimides. As summarized in Table 2, the method was effective for a wide range of substrates

Table 1 Catalyst screening for the addition of aniline to ${ }^{i} \operatorname{PrN}=\mathrm{C}=\mathrm{N}^{i} \operatorname{Pr}^{\mathrm{a})}$

\begin{tabular}{ccccc}
$>$ & & & \\
& & & & \\
\hline
\end{tabular}

a) The reaction was performed by treating 1 equiv. of aniline with 1 equiv. of ${ }^{i} \mathrm{PrN}=\mathrm{C}=\mathrm{N}^{i} \mathrm{Pr}$ and the corresponding guanidines were obtained in excellent yields. The reaction was general for aromatic amines bearing substitutions at ortho- and para-positions, and tolerated both electron deficient and electron rich amines. It is noteworthy that the reaction involving $m$-aminophenylacetylene progressed smoothly to form the corresponding guanidine while the terminal alkyne unit remained unchanged. o-Aminopyridine was less active than aniline, which may be attributed to the competitive coordination of the pyridyl group with the aluminum cation. In the case of 2,6-diisopropylaniline, the reaction afforded the corresponding guanidine in relatively low yield even with prolonged time, raised reaction temperature and $2 \mathrm{~mol} \% \mathrm{AlCl}_{3}$, indicating an obvious steric effect.

$\mathrm{AlCl}_{3}$ can also be used to catalyze the guanylation of ${ }^{i} \mathrm{PrN}=\mathrm{C}=\mathrm{N}{ }^{i} \mathrm{Pr}$ with a primary aliphatic amine such as $n-\mathrm{BuNH}_{2}$ to afford the corresponding $N, N^{\prime}, N^{\prime \prime}$-trisubstituted guanidine in good yield (Table 3, entry 1). Secondary amines are generally less reactive than primary amines toward carbodiimides. However, the reactions involving a series of cyclic secondary amines proceeded smoothly at $60^{\circ} \mathrm{C}$ in the presence of $2 \mathrm{~mol} \% \mathrm{AlCl}_{3}$ to produce the corresponding $N, N^{\prime}, N^{\prime \prime}, N^{\prime \prime}$-tetrasubstituted guanidines in good to excellent yields. This indicates that the activity of secondary amines can compete with that of primary amines under the present catalytic conditions. In addition, the reaction

Table $2 \mathrm{AlCl}_{3}$-catalyzed addition of primary aromatic amines to carbodiimides ${ }^{\mathrm{a})}$

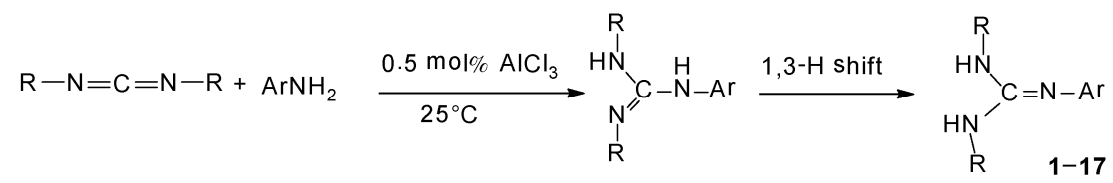

\begin{tabular}{|c|c|c|c|c|c|}
\hline Entry & $\mathrm{R}$ & $\mathrm{Ar}$ & Time & Product & Yield $(\%)^{\mathrm{b})}$ \\
\hline 1 & \multirow{12}{*}{$i-\operatorname{Pr}$} & $\mathrm{Ph}$ & $5 \mathrm{~min}$ & 1 & 97 \\
\hline 2 & & $p$-F- $\mathrm{C}_{6} \mathrm{H}_{4}$ & $5 \mathrm{~min}$ & 2 & 96 \\
\hline 3 & & $p-\mathrm{Cl}-\mathrm{C}_{6} \mathrm{H}_{4}$ & $10 \mathrm{~min}$ & 3 & 95 \\
\hline 4 & & $o-\mathrm{Cl}-\mathrm{C}_{6} \mathrm{H}_{4}$ & $2 \min$ & 4 & 97 \\
\hline 5 & & $p-\mathrm{Me}-\mathrm{C}_{6} \mathrm{H}_{4}$ & $5 \mathrm{~min}$ & 5 & 93 \\
\hline 6 & & $p-\mathrm{MeO}-\mathrm{C}_{6} \mathrm{H}_{4}$ & $2 \min$ & 6 & 96 \\
\hline 7 & & $o-\mathrm{Me}-\mathrm{C}_{6} \mathrm{H}_{4}$ & $5 \mathrm{~min}$ & 7 & 95 \\
\hline 8 & & $\alpha$-naphthyl & $10 \mathrm{~min}$ & 8 & 93 \\
\hline 9 & & $p-\mathrm{NO}_{2}-\mathrm{C}_{6} \mathrm{H}_{4}$ & $30 \mathrm{~min}$ & 9 & $96^{\mathrm{c})}$ \\
\hline 10 & & $m$-acetylenylphenyl & $2 \mathrm{~h}$ & 10 & $94^{\mathrm{d})}$ \\
\hline 11 & & $o$-pyridyl & $2 \mathrm{~h}$ & 11 & $93^{\mathrm{d})}$ \\
\hline 12 & & $2,6-i-\mathrm{Pr}_{2}-\mathrm{C}_{6} \mathrm{H}_{3}$ & $28 \mathrm{~h}$ & 12 & $66^{\mathrm{e})}$ \\
\hline 13 & \multirow{5}{*}{$\mathrm{Cy}$} & $\mathrm{Ph}$ & $30 \mathrm{~min}$ & 13 & 96 \\
\hline 14 & & $p$-F- $\mathrm{C}_{6} \mathrm{H}_{4}$ & $30 \mathrm{~min}$ & 14 & 96 \\
\hline 15 & & $o-\mathrm{Cl}-\mathrm{C}_{6} \mathrm{H}_{4}$ & $30 \mathrm{~min}$ & 15 & 96 \\
\hline 16 & & $p-\mathrm{MeO}-\mathrm{C}_{6} \mathrm{H}_{4}$ & $30 \mathrm{~min}$ & 16 & 93 \\
\hline 17 & & $o-\mathrm{Me}-\mathrm{C}_{6} \mathrm{H}_{4}$ & $30 \mathrm{~min}$ & 17 & 94 \\
\hline
\end{tabular}

a) The reaction was performed by treating 1 equiv. of amine with 1 equiv. of carbodiimide; b) isolated yield; c) 2 mol $\%$ of catalyst at $60^{\circ} \mathrm{C}$; d) $2 \mathrm{~mol} \%$ of catalyst; e) $2 \mathrm{~mol} \%$ of catalyst at $80^{\circ} \mathrm{C}$. 
Table $3 \mathrm{AlCl}_{3}$-catalyzed addition of aliphatic amines to carbodiimides ${ }^{\text {a) }}$

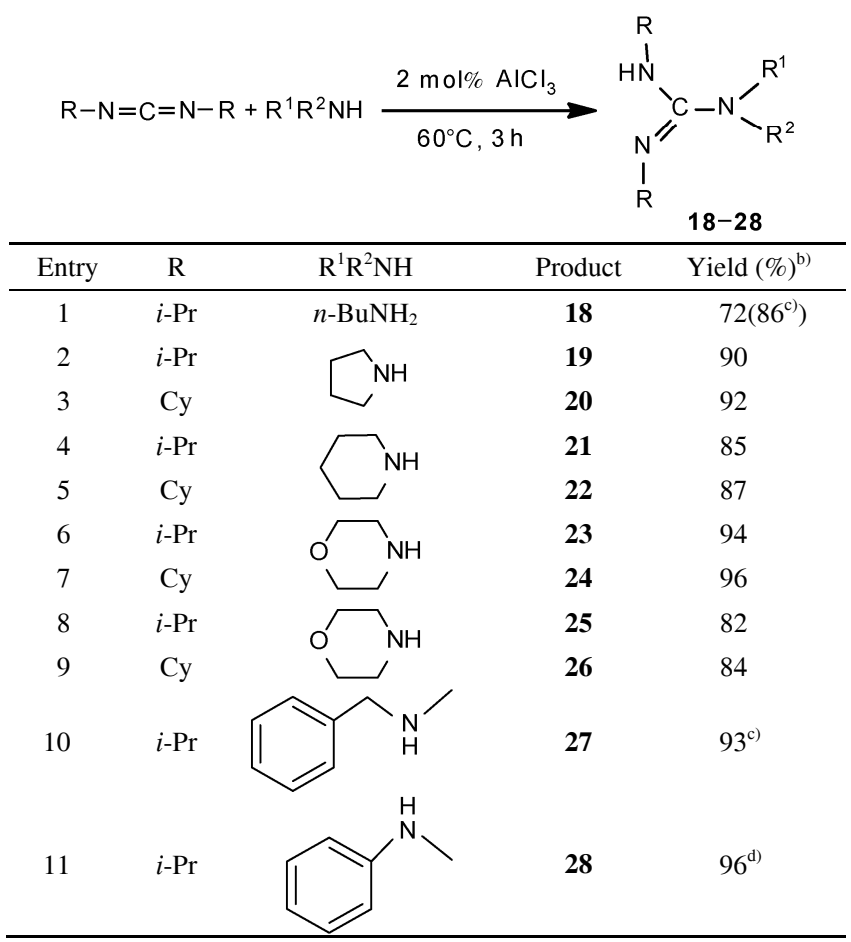

a) The reaction was performed by treating 1 equiv. of amine with 1 equiv. of carbodiimides at $60^{\circ} \mathrm{C}$ for $3 \mathrm{~h}$; b) isolated yields; c) $80^{\circ} \mathrm{C}$; d) $60^{\circ} \mathrm{C}$ for $12 \mathrm{~h}$

of ${ }^{i} \operatorname{PrN}=\mathrm{C}=\mathrm{N}^{i} \operatorname{Pr}$ with $N$-methylpiperazine, a linear secondary amine, afforded the desired product in $93 \%$ yield at $80^{\circ} \mathrm{C}$ (Table 3 , entry 10 ), revealing the activity of $\mathrm{AlCl}_{3}$ is higher than that of $\mathrm{Yb}(\mathrm{OTf})_{3}$.

To gain more information about the mechanism of the present $\mathrm{AlCl}_{3}$-catalyzed guanylation, the reaction of aniline with ${ }^{i} \mathrm{PrN}=\mathrm{C}=\mathrm{N}^{i} \mathrm{Pr}$ in chloroform was monitored by in situ infrared (IR) spectroscopy. The spectra and a plot of absorbance versus time are shown in Figure 1. The intensity of the band at $2119 \mathrm{~cm}^{-1}$, assigned to carbodiimide $(\mathrm{N}=\mathrm{C}=\mathrm{N})$, decreased rapidly when $\mathrm{AlCl}_{3}$ was added to the solution of ${ }^{i} \mathrm{PrN}=\mathrm{C}=\mathrm{N}^{i} \mathrm{Pr}$ in chloroform. At the same time, a peak appeared at $2204 \mathrm{~cm}^{-1}$, suggesting the formation of a carbon-nitrogen triple bond $(\mathrm{C} \equiv \mathrm{N})$. When aniline was added, the peak at $2204 \mathrm{~cm}^{-1}$ disappeared immediately. The change of absorbance over time indicated that both the formation of an $\mathrm{AlCl}_{3}$-carbodiimide complex and the attack of this complex by aniline are quick.

Based on the analysis of in situ IR spectra and previous work [20,22], a possible mechanism for $\mathrm{AlCl}_{3}$-catalyzed guanylation of amine with carbodiimide was proposed, as shown in Scheme 1. $\mathrm{AlCl}_{3}$ may behave as an electron-deficient species and react with a carbodiimide to yield intermediate $\mathbf{A}$. Nucleophilic addition of an amine to $\mathbf{A}$ affords B. Intramolecular proton transfer of $\mathbf{B}$ readily releases the target guanidine and regenerates $\mathrm{AlCl}_{3}$.

In summary, we have demonstrated that the guanylation

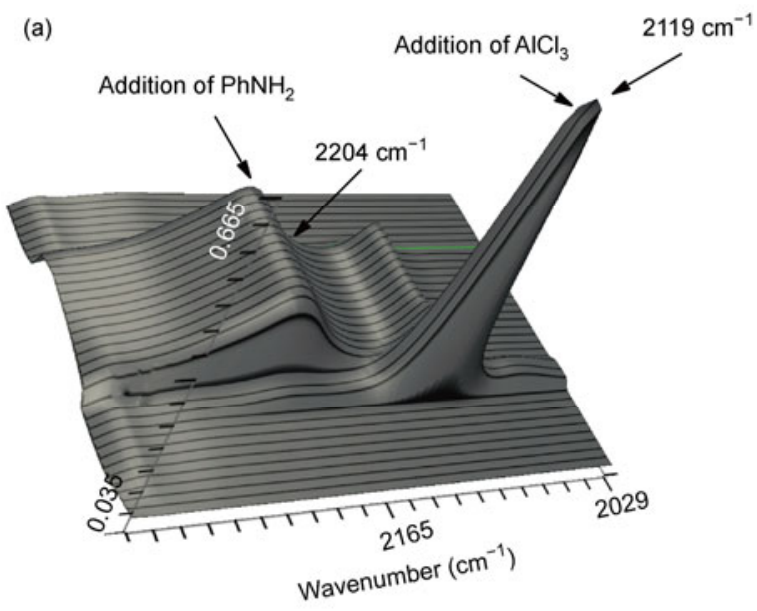

(b)

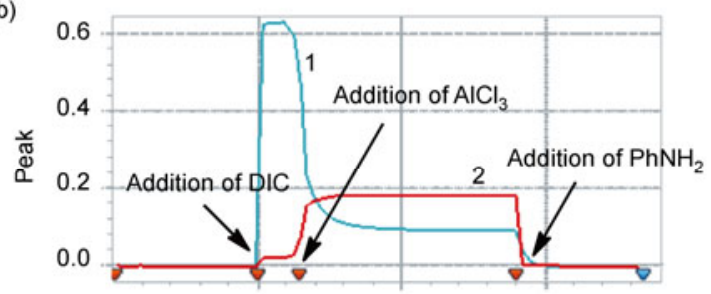

$00: 00: 00 \quad 00: 50: 00 \quad 00: 10: 00 \quad 00: 15: 00$

Relative time

Figure 1 (Color online) (a) Three-dimensional plots of IR spectra collected every $15 \mathrm{~s}$ for the reaction of aniline with ${ }^{i} \mathrm{PrN}=\mathrm{C}=\mathrm{N}^{i} \mathrm{Pr}$ in chloroform. (b) Intensities of the bands at 2119 (curve 1) and $2204 \mathrm{~cm}^{-1}$ (curve 2) upon sequential addition of ${ }^{i} \mathrm{PrN}=\mathrm{C}=\mathrm{N}^{i} \mathrm{Pr}, \mathrm{AlCl}_{3}$ and aniline to the reaction system.

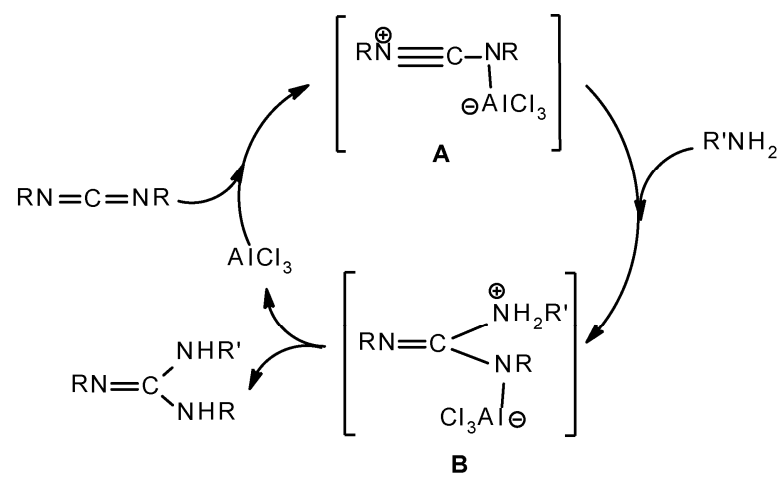

Scheme 1 Proposed mechanism for $\mathrm{AlCl}_{3}$-catalyzed addition of an amine to a carbodiimide.

of amines with carbodiimides can be effectively achieved under mild reaction conditions using catalytic amount of $\mathrm{AlCl}_{3}$, a simple and readily available reagent, allowing guanidines to be prepared efficiently in high to excellent yields. The system is applicable to a wide range of substrates including primary and secondary cyclic amines. In situ IR spectra provided some evidence for the proposed mechanism. A detailed study of the reaction mechanism is in progress in our laboratory. 
This work was supported by the National Natural Science Foundation of China (20972107, 20872106), the Department of National Education PhD Foundation, and the Priority Academic Program Development of Jiangsu Higher Education Institutions.

1 Hu L, Guo J, Magar S S, et al. J Med Chem, 1997, 40: 4281-4289

2 Ishikawa T, Kumamoto T. Synthesis, 2006, 5: 737-752

3 McManus J C, Genski T, Carey J S, et al. Synlett, 2003, 3: 369-371

4 Ishikawa T, Isobe T. Chem Eur J, 2002, 8: 552-557

5 Kovacevic B, Maksic Z B. Org Lett, 2001, 3: 1523-1526

6 Costa M, Chiusoli G P, Taffurelli D, et al. J Chem Soc Perkin Trans 1, 1998, $1541-1546$

7 Simoni D, Rondanin R, Marini M, et al. Tetrahedron Lett, 2000, 41: $1607-1610$

8 Tin M K T, Thirupathi N, Yap G P A, et al. Dalton Trans, 1999, 17: 2947-2950

9 Ong T G, Yap G P A, Richeson D S. J Am Chem Soc, 2003, 125: $8100-8101$
10 Montilla F, Pastor A, Galindo A. J Organomet Chem, 2004, 689: 993-996

11 Ong T G, O’Brien J S, Korobkov I, et al. Organometallics, 2006, 25: 4728-4730

12 Li Q, Wang S, Zhou S, et al. J Org Chem, 2007, 72: 6763-6767

13 Du Z, Li W B, Zhu X, et al. J Org Chem, 2008, 73: 8966-8972

14 Shen H, Chan H, Xie Z. Organometallics, 2006, 25: 5515-5517

15 Zhang W, Nishiura M, Hou Z. Chem Eur J, 2007, 13: 4037-4051

16 Zhang W, Nishiura M, Hou Z. Synlett, 2006, 8: 1213-1216

17 Zhang W, Nishiura M, Hou Z. J Am Chem Soc, 2005, 127: $16788-16789$

18 Alonso-Moreno C, Carrillo-Hermosilla F, Garcés A, et al. Organometallics, 2010, 29: 2789-2795

19 Li D, Guang J, Zhang W, et al. Org Biomol Chem, 2010, 8: 1816-1820

20 Zhang W, Li D, Wang Z, et al. Organometallics, 2009, 28: 882-887

21 Zhu X, Du Z, Xu F, et al. J Org Chem, 2009, 74: 6347-6349

22 Yamamoto N, Isobe M. Chem Lett, 1994, 2299-2302

Open Access This article is distributed under the terms of the Creative Commons Attribution License which permits any use, distribution, and reproduction in any medium, provided the original author(s) and source are credited. 